\title{
Endograft repair for pseudoaneurysms and penetrating ulcers of the ascending aorta
}

\author{
Gabriele Piffaretti, MD, PhD, ${ }^{\mathrm{a}}$ Mario Galli, MD, ${ }^{\mathrm{b}}$ Chiara Lomazzi, MD, ${ }^{\mathrm{c}}$ Marco Franchin, MD, \\ Patrizio Castelli, MD, ${ }^{a}$ Giovanni Mariscalco, $\mathrm{MD}, \mathrm{PhD},{ }^{\mathrm{d}}$ and Santi Trimarchi, $\mathrm{MD}, \mathrm{PhD}^{\mathrm{c}}$
}

\section{ABSTRACT}

Objective: The aim of this paper is to report midterm results of thoracic endovascular aortic repair (TEVAR) for ascending aortic pseudoaneurysms (AAPs) and penetrating aortic ulcers (PAUs) of the ascending aorta.

Methods: This study was retrospective and performed at tertiary centers. Eight patients with AAPs $(n=5)$ and PAUs $(n=3)$ received total endovascular repair of the ascending aorta. Patients with a history of type A aortic dissection or fusiform aneurysm were excluded. All patients analyzed were considered to be at high risk for open repair at the time of presentation.

Results: Urgent intervention was performed in $6(75 \%)$ cases. Primary clinical success was achieved in $7(87.5 \%)$ cases. A low-flow type 3 endoleak remained asymptomatic and was managed conservatively. No TEVAR-related in-hospital mortality, primary conversion, cerebrovascular accidents, valve impairment, or myocardial infarction occurred. All patients were discharged home, alive and independent, after a median length of stay of 6 (range: 5-24) days. No patient was lost at a mean follow-up of $40 \pm 33$ (range: 4-93) months. Ongoing primary clinical success was maintained in all but 1 patient (type 3 endoleak): aortically related reintervention was never required. No endograft breakage or migration was observed. At 1-year follow-up, 7 (87.5\%) aortic lesions had significant reduction in diameter $(\geq 5 \mathrm{~mm})$.

Conclusions: Ascending TEVAR was feasible, safe, and effective for AAPs and PAUs. In a very select subset of lesions, midterm results were favorable, with both standard and custom-designed endografts. (J Thorac Cardiovasc Surg 2016;151:1606-14)

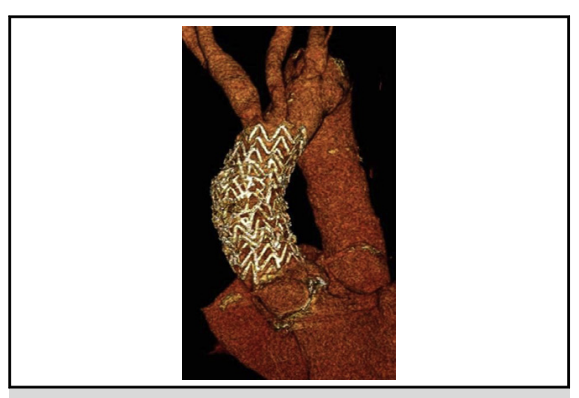

Photo of an ascending aortic pseudoaneurysm treated (off-label) with 2 abdominal aortic cuffs.

\section{Central Message}

Ascending TEVAR was feasible, safe, and effective for a subset of pseudoaneurysms and penetrating ulcers, with favorable midterm results.

\section{Perspective \\ Thoracic endovascular aortic repair has emerged as an alternative method of treatment for thoracic aortic diseases. The ascending aorta is the new "frontier" of TEVAR. In a very select subset of lesions, TEVAR may be preferred for patients who may not be able to tolerate a complex and risky operation, or it can be adopted as a bridge treatment, making emergent into elective interventions.}

See Editorial Commentary page 1615.
Thoracic endovascular aortic repair (TEVAR) has evolved rapidly, becoming an effective alternative to open repair for descending and aortic arch pathologies. ${ }^{1,2}$ More

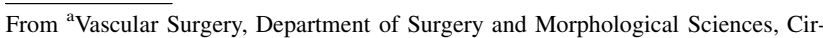
colo University Teaching Hospital, University of Insubria School of Medicine, Varese, Italy; ' Interventional Cardiology Department of Medicine, S. Anna Hospital, Como; ${ }^{c}$ Vascular Surgery II and Thoracic Aortic Research Center, IRCCS Policlinico San Donato Teaching Hospital, University of Milan School of Medicine, Milan, Italy; and ${ }^{\mathrm{d} C a r d i a c}$ Surgery, Glenfield Hospital, University of Leicester, Leicester, United Kingdom.

Gabriele Piffaretti and Mario Galli are co-first authors.

Received for publication July 28, 2015; revisions received Dec 18, 2015; accepted for publication Dec 24, 2015; available ahead of print Feb 9, 2016.

Address for reprints: Gabriele Piffaretti, MD, PhD, Vascular Surgery- Department of Surgery and Morphological Sciences, Circolo University Teaching Hospital, University of Insubria School of Medicine, Via Guicciardini, 921100 , Varese, Italy (E-mail: gabriele.piffaretti@uninsubria.it).

$0022-5223 / \$ 36.00$

Copyright (c) 2016 by The American Association for Thoracic Surgery

http://dx.doi.org/10.1016/j.jtcvs.2015.12.055
}

recently, ascending aorta has been targeted as the new frontier of endovascular repair, and currently, few series of ascending TEVAR have been reported. ${ }^{3-8}$ Although several technical concerns remain, including anatomical landmarks, hemodynamic forces, and endograft performance, favorable results have been reported in a very select group of morphologies..$^{5-8}$ Ascending aortic pseudoaneurysms (AAPs) are an uncommon, but potentially life-threatening, complication after aortic surgery; however, regardless of the etiology, reoperation for AAPs entails a hospital mortality rate

Scanning this QR code will take you to the article title page. 


\section{Abbreviations and Acronyms \\ AAP = ascending aortic pseudoaneurysm \\ EuroSCORE $=$ European system for cardiac operative risk evaluation \\ PAU = penetrating aortic ulcer \\ TEE $\quad=$ transesophageal echocardiography \\ TEVAR $=$ thoracic endovascular aortic repair}

of $6.9 \%$ to $15.4 \%$, even in experienced centers. ${ }^{9,10}$ Similarly, penetrating aortic ulcer (PAU) of the ascending aorta has not been reported frequently, but it has exhibited a high risk of rupture at presentation and an in-hospital mortality rate of up to $16 \% .^{11}$ Pseudoaneurysms and PAUs are usually saccular lesions of the aorta, which proved to be an attractive site for TEVAR, because of the focal involvement of the aortic wall, and can be effective in high-risk patients. ${ }^{3,12}$ The aim of the current paper is to report midterm results of TEVAR for pseudoaneurysms and PAUs of the ascending aorta.

\section{METHODS}

\section{Patient Cohort and Preoperative Procedures}

This study is retrospective, involving 2 cardiovascular surgery units at referring tertiary hospitals. All patients were identified who had AAP and PAU and received total TEVAR of the ascending aorta between 2006 and 2014. Patients with type A aortic dissection or fusiform aneurysm of the ascending aorta were excluded from this case series. All patients analyzed were considered to be at high risk for open repair at the time of presentation, because of the EuroSCORE, the performance status, and the opinions expressed in a multidisciplinary team debate (among cardiac and vascular surgeons, interventional cardiologists, and anesthesiology staff). ${ }^{13}$ The protocol and informed consent were approved by the institutional review board; after a detailed discussion on the risks and benefits of an open repair versus an endovascular alternative, informed consent to proceed with TEVAR was obtained from all patients. Complete thoracoabdominal computed tomography angiography was performed in all cases, to evaluate the anatomy of the ascending aorta and optimize endograft selection. The type of endograft was determined by the ascending aortic length and the diameter, measured immediately above the sinotubular junction (proximal landing zone at the tubular portion of the ascending aorta). Supra-aortic trunk and brain vessels were evaluated to assess both the integrity of the Willis circle and the dominance of the vertebral arteries, as well as to plan aortic arch debranching if needed.

\section{Operative Technique}

The TEVAR procedure was performed with patients under general anesthesia, with the cardiac perfusion team on standby to assist if needed; transesophageal echocardiography (TEE) monitoring was used in all cases. During the intervention, intravenous weight-adjusted heparinization was administered, to maintain an activated clotting time of $\geq 250$ seconds throughout the procedure. The endograft insertion site was selected depending on sizing of the access artery, device characteristics, and ascending/arch anatomy. Preliminary angiography was performed in all cases, to identify the ostium of the coronary arteries and the brachiocephalic trunk takeoff point; the brachiochephalic trunk was the anatomical border of the distal landing zone. During the advancement of the endograft, TEE confirmed the absence of valve impairment; in all cases, the endograft was deployed under temporary overdrive cardiac pacing (generally, $190 \mathrm{bt} / \mathrm{min}$ ), via a transvenous pacing catheter. Considering both the fact that we treated either native or "grafted" aortas, and the focal nature of these lesions, we chose to use a $10 \%$ to $15 \%$ range of oversizing, to prevent endograft-induced retrograde dissection. Final control angiography and TEE were used to confirm the exclusion of the aortic lesion, competency of the aortic valve, and patency of the coronary arteries and the supra-aortic vessels.

\section{Postoperative Protocol}

Postoperatively, every patient started clopidogrel bisulfate at $75 \mathrm{mg}$ per day, plus aspirin (Cardioaspirin; Bayer, Rome, Italy) at $100 \mathrm{mg}$; alternatively, warfarin sodium (Coumadin; Bristol-Myers Squibb, Rome, Italy) at $5 \mathrm{mg}$ was used for patients who were already on an anticoagulant regimen preoperatively. Transthoracic echocardiogram and computed tomography angiography were performed before discharge. Follow-up imaging included chest radiographs and triple-phase computed tomography angiography at 1,4 , and 12 months after intervention, and annually thereafter. Either abdominal and thoracic standard devices (Excluder; W.L. Gore and Associates, Flagstaff, Ariz, and TX-2; Cook, Bloomington, Ind) or a custom-designed endograft (Relay; Bolton Medical, Sunrise, Fla) were implanted.

\section{Definition}

All variables analyzed in the study were defined according to the Society of Thoracic Surgeons adult database. ${ }^{14}$ Morphological characteristics and outcomes were classified according to the Society for Vascular Surgery ad hoc committee on TEVAR reporting standards. ${ }^{15}$ The location of the aortic lesion was described according to the various segments of the ascending aorta: "zone 1" includes the aortic root, sinotubular junction, and proximal third of the tubular portion of the ascending aorta; "zone 2," which does not have any branches, corresponds to the middle-third tubular portion of the ascending aorta; and "zone 3" represents the distal third tubular portion of the ascending aorta, reaching the proximal aspect of the brachiocephalic trunk. ${ }^{16}$ Clinical data were prospectively recorded. Results are expressed as mean \pm standard deviation for continuous variables, and frequencies for categorical ones.

\section{RESULTS \\ Patient Data}

We treated 8 patients: $6(75 \%)$ were men, with mean age $71 \pm 7$ (range: 58-81) years. Comorbidities and risk factors are shown in Table 1 . Six (75\%) patients had a history of previous major cardiac operation; median delay from the first cardiac operation was 12 (range: 6-108) months. Indications for TEVAR were $\mathrm{AAP}(\mathrm{n}=5)$ and PAU $(\mathrm{n}=3)$. Etiology of AAP included cannulation site $(n=4)$ and suture line disruption $(n=1)$; AAP was mycotic in 1 case. All PAUs were degenerative in etiology. Overall, 5 $(62.5 \%)$ patients were symptomatic for acute thoracic pain. Two AAPs were asymptomatic, detected during follow-up examinations (Figure 1). Aortic lesion was located in "zone 1" in $1(12.5 \%)$ case, "zone $2 "$ in $5(62.5 \%)$, and "zone 3 " in $2(25 \%)$. The mean maximum aortic lesion diameter was $48 \pm 15$ (range: $20-70$ ) $\mathrm{mm}$. The proximal ascending aorta diameter at the proximal landing zone was $32 \pm 7$ (range: 22-41) $\mathrm{mm}$. The mean distance between the coronary arteries/bypass graft ostia and the brachiocephalic trunk was $74.5 \pm 7$ (range: $48-90) \mathrm{mm}$. 
TABLE 1. Comorbidities and risk factors of the cohort

\begin{tabular}{lc}
\hline Comorbidity/risk factor & n (\%) or mean \pm SD \\
\hline Hypertension & $8(100)$ \\
Diabetes & $6(75)$ \\
IHD & $4(50)$ \\
CRI (CKD stage 3-4) & $4(50)$ \\
COPD (GOLD stage $\geq 2)$ & $3(37.5)$ \\
Valve disease & $2(25)$ \\
CVA & $2(25)$ \\
Atrial fibrillation & $2(25)$ \\
Porcelain aorta & $1(12.5)$ \\
Previous cardiac intervention & \\
CABG & 3 \\
Valve replacement & 2 \\
Bentall procedure & 1 \\
EuroSCORE & $13.5 \pm 5.1(8.5-23.8)$ \\
\hline
\end{tabular}

$S D$, Standard deviation; IHD, ischemic heart disease; CRI, chronic renal insufficiency; $C K D$, chronic kidney disease; $C O P D$, chronic obstructive pulmonary disease; GOLD, Global Initiative for Chronic Obstructive Lung Disease; $C V A$, history of cerebrovascular accidents; $C A B G$, coronary artery bypass graft; EuroSCORE, European system for cardiac operative risk evaluation.

\section{Operative Data}

Urgent intervention was performed in $6(75 \%)$ cases. The right common femoral artery access was used in $5(62.5 \%)$ cases, the left subclavian artery in $2(25 \%)$, and a right subclavian artery in $1(12.5 \%)$. A summary of operative details is shown in Table 2. A standard endograft was used in $6(75 \%)$ cases; 1 of the 2 custom-designed endografts was reversed tapered. The mean endograft diameter was $40 \pm 6$ (range: $30-50 \mathrm{~mm}$ ), and the mean length was $58 \pm 10$ (range: 45-70) $\mathrm{mm}$. Five (62.5\%) patients received 1 endograft; $3(37.5 \%)$ received $\geq 2$ endografts. An additional procedure was required in 1 $(12.5 \%)$ patient: a common femoral endarterectomy with patch plasty was needed at the end of the procedure after retrieval of the device.

\section{In-Hospital Results}

Primary clinical success was achieved in 7 (87.5\%) patients. One patient with an acute symptomatic PAU treated with multiple endografts had a type 3 endoleak at the end of the intervention. This endoleak was late in appearance and with a very limited reperfusion of the aortic lesion. No TEVAR-related in-hospital mortality occurred. Primary conversion was never required. TEVAR-related complication included $1(12.5 \%)$ mild event: A femoral pseudoaneurysm was successfully excluded with a thrombin injection. The low-flow type 3 endoleak remained asymptomatic and was managed conservatively. Cerebrovascular accidents, valve impairment, and myocardial infarction did not occur. All patients were discharged home, alive and independent. The median length of stay was 6 (range: 5-24) days.
The patient with the mycotic AAP remained on lifelong antibiotic therapy, given the risk of life-threatening endograft infection.

\section{Late Results}

No patient was lost at a mean follow-up of $40 \pm 33$ (range: 4-93) months. Ongoing primary clinical success was maintained in all patients. Specifically, aortically related reintervention, either open or endovascular, was never required. No patient died during follow-up. Endograft breakage, migration, and superinfection were not observed. Of the 8 devices implanted, $7(87.5 \%)$ had appropriate follow-up imaging for evaluation at 1 year, $5(62.5 \%)$ at 3 years (Figure 2), and $3(37.5 \%)$ at 5 years (Figure 3 ). At 1-year follow-up, $7(87.5 \%)$ aortic lesions had significant reduction in diameter $(\geq 5 \mathrm{~mm})$. The type 3 endoleak is still under surveillance, but neither shrinkage nor sac enlargement was observed (Figure 4).

\section{DISCUSSION}

Pseudoaneurysms and PAUs are saccular lesions that occur in rare cases at the ascending aorta. ${ }^{3,5,11,17}$ Although AAPs most frequently develop from cannulation sites or graft suture lines in patients who have a history of cardiac operations, PAUs are generally a natural evolution of an atherosclerotic plaque rupture of the aortic wall. ${ }^{4,8,11}$ Most authors agree that, regardless of their etiology, these lesions should be managed operatively-AAPs because of life-threatening complications after their formation, and PAUs because of their high propensity to rupture despite optimal medical management. ${ }^{4,10,11}$ However, open repair of AAPs carries high risk owing to reoperation, whereas operative risk of PAUs is mainly related to the multiple comorbidities the patients bring with them. ${ }^{9-11}$ For these focal lesions, TEVAR emerged as a potential alternative to redo open repair, especially for high-risk patients. TEVAR avoids the risks of repeat exposure and minimizes the adverse effects of complex maneuvers in patients who are typically older and have important risk factors. We have identified 40 cases of AAPs and PAUs treated with TEVAR so far: TEVAR-related mortality was $5 \%$, which is significantly lower than the $6.9 \%$ to $15.4 \%$ for conventional open repair, even at centers with highly experienced surgeons. ${ }^{4-8,18-26}$ In particular, the rapidity and minimal invasiveness of TEVAR could add value, in an emergent setting or for patients who may not have tolerated a complex and risky operation, or may be adopted as a bridge treatment, to change an emergent intervention into an elective one. ${ }^{7}$

In a large cohort series, the ruptured rate of ascending PAUs at presentation has been reported to be as much as $38 \%$; they required urgent operation in $20 \%$ to $45 \%$ of cases. ${ }^{9-11}$ In our case series, no patient presented with aortic rupture, but $75 \%$ of the cases were treated urgently 


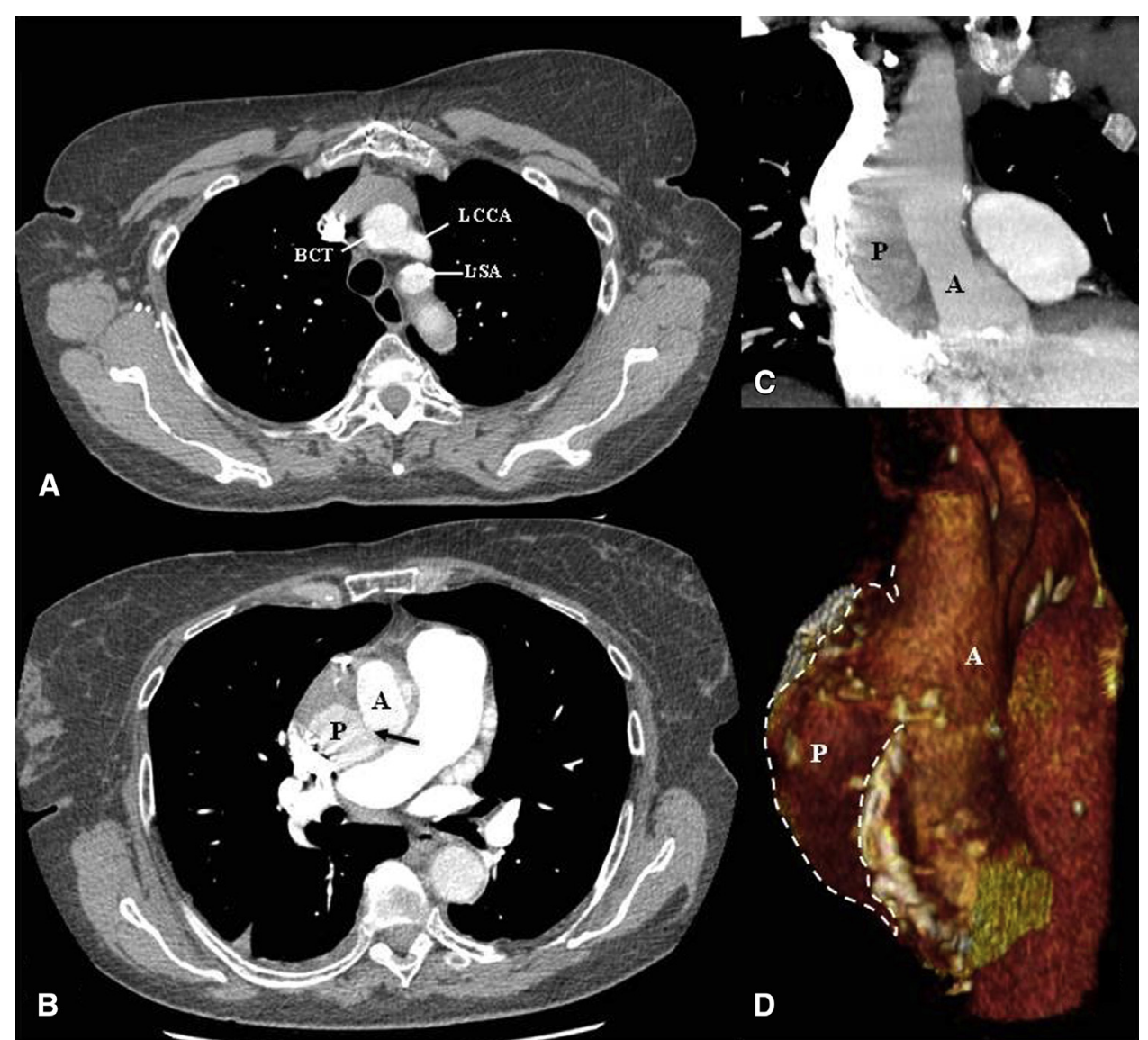

FIGURE 1. Preliminary computed angiography of a suture-line disruption $A A P$ (patient \#7) shows the following: (A) the variant of the supra-aortic vessels with a common origin of the brachiocephalic trunk and left common carotid artery; (B) the origin (arrow) of the AAP (marked as $P$ ) developed from a previous ascending aortic graft replacement (marked as $A$ ); (C) multiplanar reconstruction; (D) volume rendering reconstruction indicating the enormity of the pseudoaneurysm. BCT, Brachiocephalic trunk; LCCA, left common carotid artery; LSA, left subclavian artery; $P$, pseudoaneurysm; A, aorta.

because of typical symptoms of the acute aortic syndrome. Although the preoperative score predicted a mean $13.5 \%$ mortality rate, in-hospital mortality did not occur and all patients were discharged to home and independent living.

Thoracic endovascular aortic repair is a recent application for ascending aortic diseases; therefore, long-term follow-up results are limited. In the 3 largest series of ascending TEVAR, the reintervention rate at 12 months has been reported to be between $16.7 \%$ and $27 \% ., 7,8$ Our results compare favorably: at longer followup times, we did not observe aortically related mortality or a need for reintervention; remarkably, a stable exclusion or shrinkage of the aortic lesion was observed in nearly $90 \%$ of cases. Midterm results of TEVAR for AAPs and

TABLE 2. Case series summary: anatomical and technical details

\begin{tabular}{|c|c|c|c|c|c|c|c|c|c|c|c|c|c|}
\hline Gender & $\begin{array}{c}\text { Age } \\
(\mathbf{y})\end{array}$ & $\begin{array}{c}\text { CS } \\
\text { type }\end{array}$ & Etiology & Infection & Symptomatic & TEVAR & EuroSCORE & Diameter & ASCAD & CA-IA & $\begin{array}{l}\text { EG } \\
\text { type }\end{array}$ & EGD & $\begin{array}{r}\text { EG } \\
\text { (n) } \\
\end{array}$ \\
\hline Male & 57 & CABG & Cannulation & No & No & Elective & 8.80 & 20 & 26 & 70 & $\mathrm{CM}$ & $30 \times 65$ & 1 \\
\hline Male & 71 & BAV & Cannulation & No & Thoracic pain & Urgent & 9.93 & 70 & 30 & 80 & OS & $36 \times 45$ & 3 \\
\hline Male & 73 & CABG & PAU & No & Thoracic pain & Urgent & 8.46 & 53 & 35 & 75 & $\mathrm{OS}$ & $45 \times 50$ & 1 \\
\hline Male & 81 & no & PAU & No & Thoracic pain & Urgent & 11.75 & 60 & 41 & 83 & OS & $45 \times 60$ & 1 \\
\hline Female & 73 & BAV & cannulation & No & Thoracic pain & Urgent & 16.49 & 35 & 37 & 90 & OS & $45 \times 60$ & 2 \\
\hline Male & 65 & CABG & Cannulation & Yes & Thoracic pain & Urgent & 14.49 & 41 & 39 & 80 & OS & $45 \times 70$ & 1 \\
\hline Female & 75 & Bentall & Suture line & No & No & Elective & 23.79 & 53 & 22 & 70 & $\mathrm{CM}$ & $38-48 \times 70$ & 1 \\
\hline Male & 70 & no & PAU & No & Thoracic pain & Urgent & 14.25 & 50 & 29 & 48 & OS & $36 \times 45$ & 4 \\
\hline
\end{tabular}

Diameters and distance are given in mm. CS, (previous) Cardiac surgery; TEVAR, thoracic endovascular aortic repair; EuroSCORE, European system for cardiac operative risk evaluation; $A S C A D$, ascending aorta diameter; $C A-I A$, coronary arteries ostia-to-innominate artery distance; $E G$, endograft; $E G D$, endograft diameter; $C A B G$, coronary artery bypass graft; $C M$, custom-designed; $B A V$, biological aortic repair; $O S$, off-the-shelf; $P A U$, penetrating aortic ulcer. 


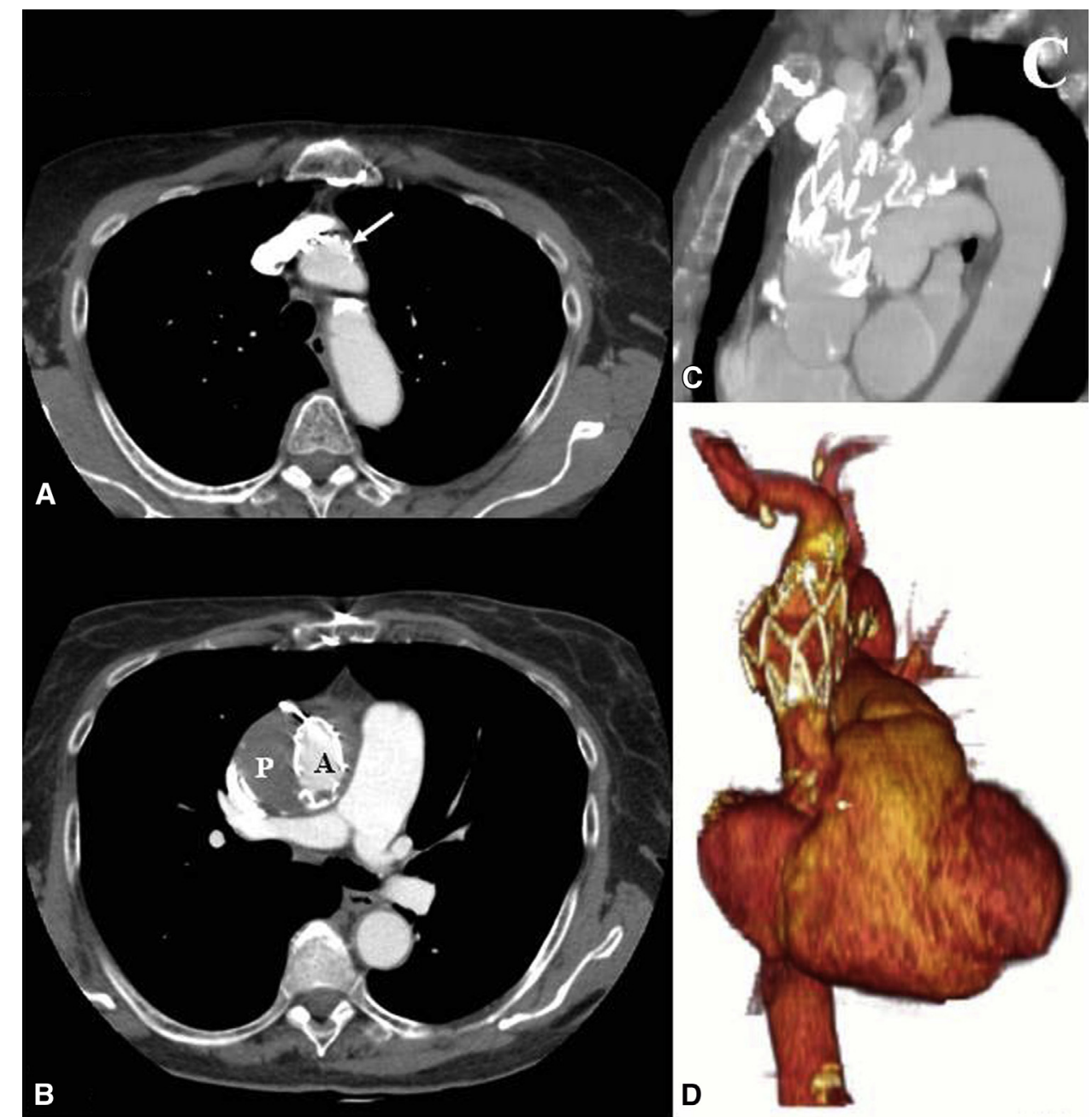

FIGURE 2. Postoperative computed tomography-angiography control of Figure 1 AAP: (A) regular patency of the supra-aortic vessels with the distal edge (arrow) of the custom-designed endograft deployed in proximity to the brachiocephalic trunk take-off point; (B) complete exclusion of the AAP (marked as $P$ ), and full expansion of the ascending endograft (marked with $A$ ); (C) multiplanar reconstruction; (D) volume rendering reconstruction at 24 months. $P$, Pseudoaneurysm; $A$, aorta.

PAUs lead to better outcomes, compared with endovascular treatment of aneurysms or acute type A dissection. ${ }^{3,16-35}$ In a series on aneurysms, Kolvenbach and colleagues ${ }^{3}$ reported type 1 endoleaks, severe aortic incompetence, kink and compression of the endograft, and overstenting of the brachiocephalic artery. In acute type A dissection series, additional stent grafting was reported in up to $40 \%$ of cases, and type 1 endoleaks in $25 \%$ with a need for reintervention in $50 \%$ of them, and a redissection rate of nearly $7 \% .^{16,27,28}$

Technical aspects in TEVAR procedures are highly critical, even in the ascending aorta, because it poses several anatomical challenges, such as the mismatch between lengths of the inner and outer curvatures, the distance from the sinotubular junction to the brachiocephalic trunk, and the proximity of the coronary arteries. Thus, no dedicated device is available for ascending TEVAR, and most of the published cases have been treated with the off-label deployment of standard thoracic or abdominal endografts. ${ }^{3-8,18-26}$ One method applied to address the problem of various aortic lengths, is use of 2 or 3 stacked short endografts, namely abdominal aortic extender cuffs; however, this option may lead to problems such as dislodgment, migration, and endoleaks. ${ }^{3,7}$ We used this technique in 3 cases because the short neck length of these focal lesions facilitated deployment of short standard endografts in urgent cases. However, an additional type 3 endoleak occurred in our experience. Another approach is implantation of standard thoracic endografts. In those cases, it has been reported to cut the standard thoracic endografts intraoperatively after partial deployment on the operating table, and reloaded it to optimize discrepancies in length measurements. ${ }^{3}$ 


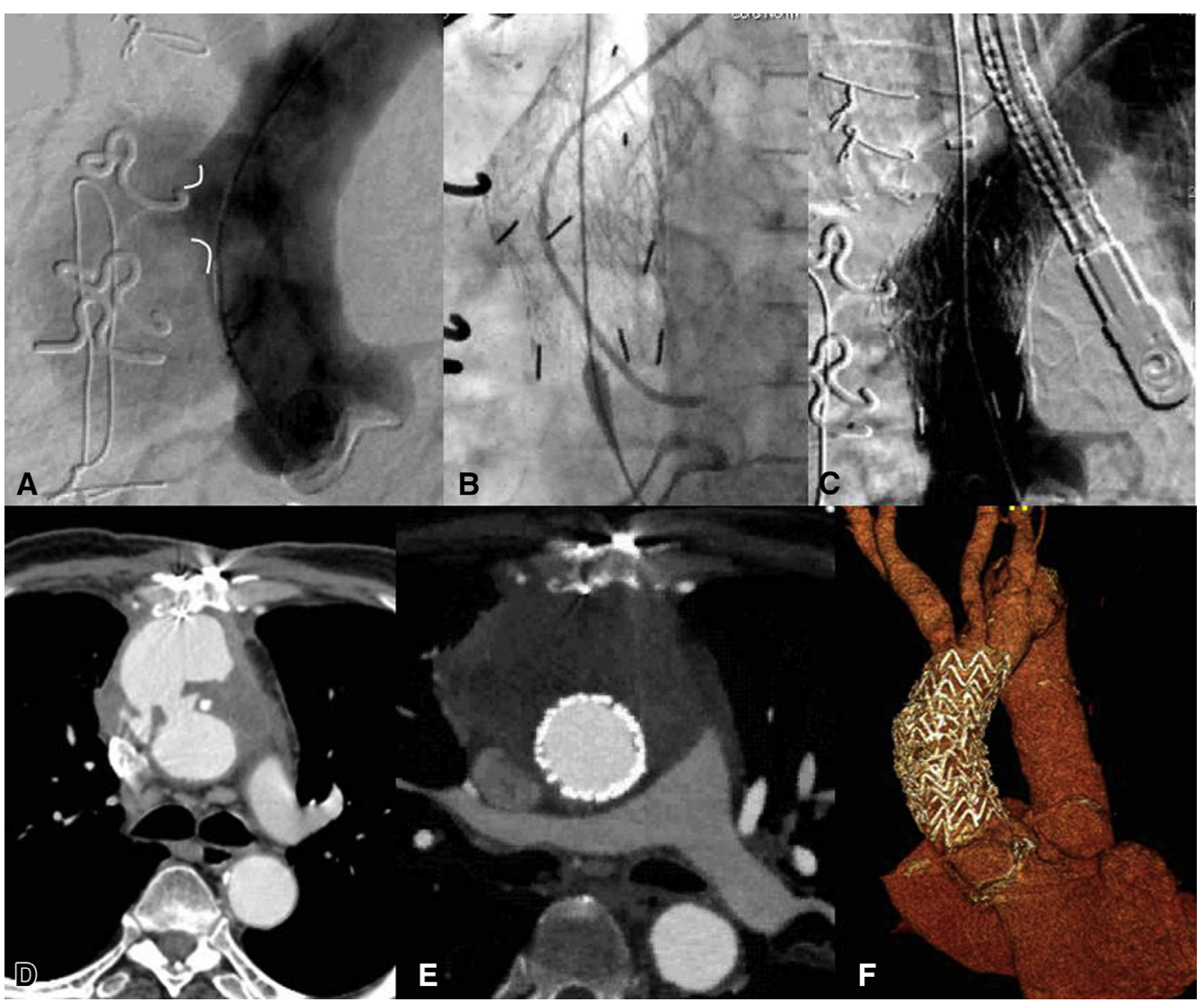

FIGURE 3. Intraoperative angiography of an AAP (patient \#5) shows the following: (A) the neck located in zone 2 (lines); (B) the deployment of 2 short standard abdominal endografts; (C) final control angiogram with complete exclusion of the AAP and an absence of endoleaks; (D) preliminary CT-A of the same AAP; (E) 12-month follow-up CT-A of the stable exclusion of the AAP with no endoleaks, and the full expansion and integrity of the endografts; (F) volume rendering reconstruction at 24 months.

All these tricks underscore the limitations of current devices, especially for lengthier lesions. Although expensive and time consuming to manufacture, a custom-designed endograft allows total endovascular treatment while accommodating all the anatomical landmarks and variation in size of the ascending aorta. ${ }^{4,23}$ For primarily this reason, we planned to use a custom-designed endograft whenever possible.

Another anatomical/technical factor needs to be taken into consideration: The advancement and deployment of the endograft over the aortic valve can result in temporary aortic impairment, especially in patients with mechanical valves. ${ }^{3,7}$ During this maneuver, temporary pacing was always valuable, because it is rapid, controllable, and immediately reversible. In addition, this approach allows a quick and precise release of the endograft in zone 1 of the ascending aorta, and limits the risk of distal migration., ${ }^{4,22,26}$ Advancement of the endograft is strongly related to another important factor-the access vessel. This feature is the only one that differs in our experience, compared with the 2 largest published studies. ${ }^{7,8}$ In fact, although all the procedures were performed with heparin for anticoagulation, TEE for deployment control and valve competence, and rapid pacing (except in 1 case of full cardiopulmonary bypass; $3.5 \%$ of 28 cases overall) for precise deployment, they used different "remote" access approaches, with a transapical approach used in most of them, to make lesion engagement and endograft deployment easier. The transapical approach in ascending TEVAR has been advocated to overcome some limitations of current "off-the-shelf" off-label devices that result from the inadequate length of current delivery systems, and the issues of retrograde passage across the arch and the various lengths of the ascending aorta curvatures. Nevertheless, the transapical approach has been recognized to be a significant predictor of worse outcomes. ${ }^{36}$ Second, our lesions were suitable to be treated with more-remote and less-invasive surgical approaches. ${ }^{20,29}$ Lastly, in our series, $3(37.5 \%)$ patients had atrioventricular repair, 1 being mechanical, which has been recognized as a clear contraindication for the transapical approach, to avoid valve impairment.

Given the unavailability of dedicated endografts, only standard "off-the-shelf" devices were evaluated, in terms 


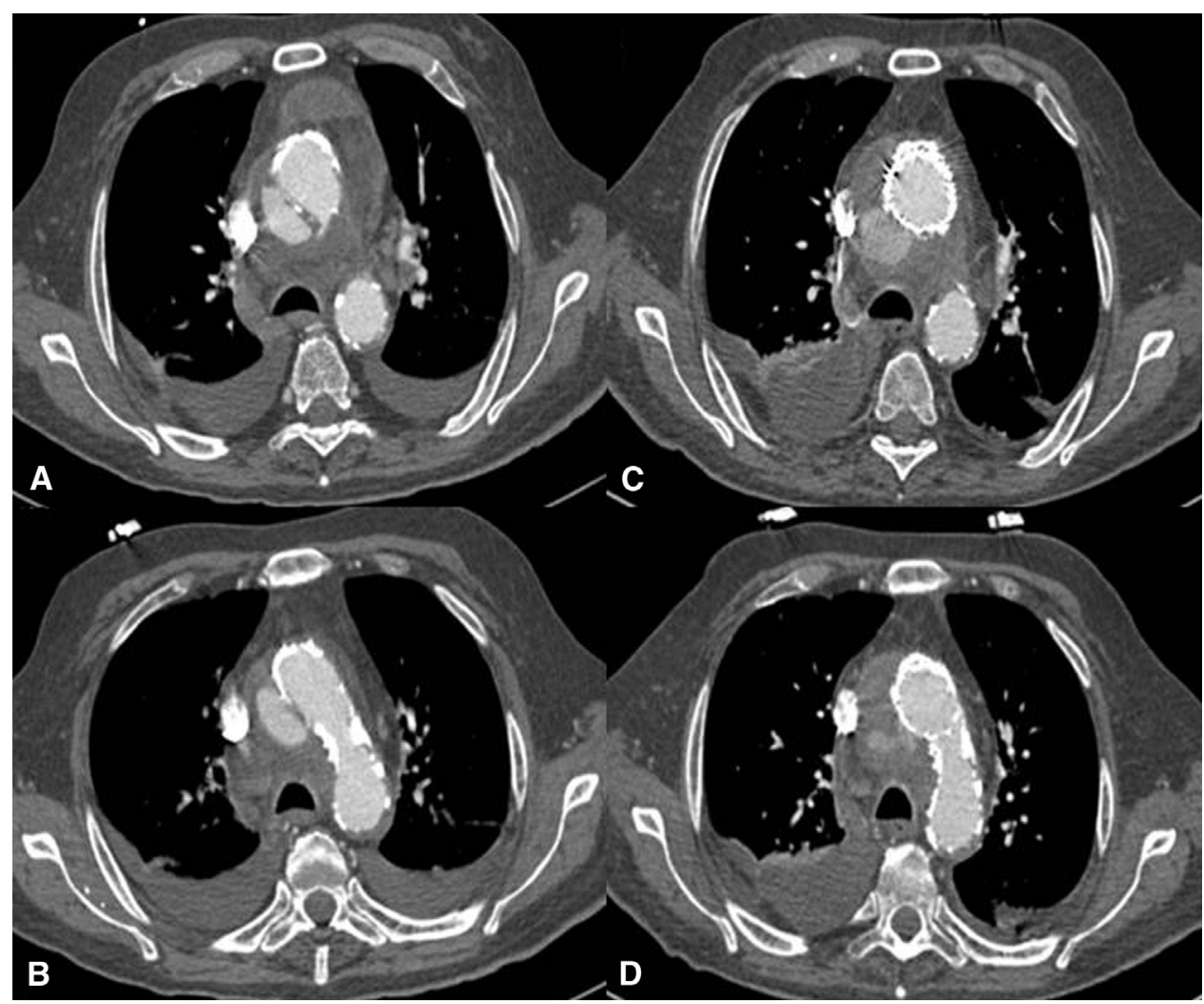

FIGURE 4. Preoperative (A and B) CT-A of a penetrating aortic ulcer of the ascending aorta (patient \#8); postoperative (C and D) CT-A control showing the presence of a type 3 endoleak. This patient had received a descending thoracic endovascular aortic repair before this ascending repair.

of sizing and immediate availability. Further, all these factors have been matched with the need for a longer shaft. Thus, at this time, use of a specific selection criterion is not advisable. Considering the endograft deployment, and the acute nature of most of these procedures, anatomical feasibility dictates the choice of the endograft, as has been the case since the first report of ascending TEVAR, and for subsequent endovascular implants.

Infection is a known cause among etiologies of AAPs. ${ }^{4,10,17}$ TEVAR for mycotic AAP has been used after various types of major cardiac intervention: valve replacement, orthotopic heart transplant, and coronary artery bypass grafting. ${ }^{17,26,29}$ Although high-virulence organisms grew in most of these cases, good results have been reported, even in the urgent setting. ${ }^{26,29}$ In this type of AAP, long-term follow-up remains a concern because of the high risk of endograft infection. A recent European multicenter collaboration study on endovascular treatment of mycotic aortic aneurysms showed that $82 \%$ of endograft-related infection occurred within the first 12 months, and can be fatal. ${ }^{17}$ All patients so far reported to have been treated with ascending TEVAR for mycotic AAPs have survived. In particular, Gelpi and colleagues ${ }^{26}$ and Heye and colleagues ${ }^{30}$ reported appropriate follow-up CT imaging at 9 and 12 months after the procedure, respectively. Their AAPs were excluded, with progressive shrinkage and no recurrence of infection. TEVAR, combined with antibiotic therapy, may offer an alternative to open repair, even with these high-risk mycotic lesions. ${ }^{17,26}$

The increasing number of publications indicates the popularity that TEVAR is gaining for use with ascending aortic pathologies. Thrombin injection and endovascular plugging have been widely described in treating AAPs, but these approaches had inconsistent results. ${ }^{7,31,32}$ Fenestrated or branched endografts, flow-modulator stents, and multiple-barrel grafts are novel, totally endovascular strategies used to preserve supra-aortic branches in ascending/arch TEVARs, but they are technically demanding and thus are not widely reported. ${ }^{33-35}$ Hybrid repair increases operative landing zones and maintains supra-aortic vessel patency, but it still requires open surgery with extra-anatomical bypass. ${ }^{2}$ Branched endografts are a new option adopted mainly for arch aneurysms, and these endografts have been accompanied by clinical and technical issues. ${ }^{21,24}$ Although current series are limited in number, TEVAR can be a viable and available technical alternative, because it can produce the same results and is in keeping with the concepts of conventional prosthetic reconstruction. 
Two important limitations of our study are the small number of patients, and use of midterm results. Both of these are common in the available literature because we still consider open repair the gold standard. The positive counterpart to this limitation is that only focal lesions have been treated, which provides morphological homogeneity.

\section{CONCLUSIONS}

In our experience, TEVAR for pseudoaneurysms and PAUs of the ascending aorta was feasible, safe, and effective. Appropriate patient selection for TEVAR in the management of ascending aortic pathologies is critical, as are lesion selection and even endograft selection. In these cases, satisfactory midterm results have been observed in patients who are at highest or even prohibitive risk, although long-term results need to be confirmed.

\section{Conflict of Interest Statement}

Authors have nothing to disclose with regard to commercial support.

\section{References}

1. Gopaldas RR, Huh J, Dao TK, LeMaire SA, Chu D, Bakaeen FG, et al. Superior nationwide outcomes of endovascular versus open repair for isolated descending thoracic aortic aneurysm in 11,669 patients. J Thorac Cardiovasc Surg. 2010; 140:1001-110.

2. Sood V, Patel HJ, Williams DM, Dasika NL, Yang B, Deeb GM. Open and endovascular repair of the nontraumatic isolated aortic arch aneurysm. $J$ Vasc Surg. 2014;60:57-63

3. Kolvenbach RR, Karmeli R, Pinter LS, Zhu Y, Lin F, Wassiljew S, et al. Endovascular management of ascending aortic pathology. J Vasc Surg. 2011; 53:1431-7.

4. Preventza O, Henry MJ, Cheong BY, Coselli JS. Endovascular repair of the ascending aorta: when and how to implement the current technology. Ann Thorac Surg. 2014;97:1555-60.

5. Bernardes RC, Navarro TP, Reis FR, Lima LC, Monteiro EL, Procopio RJ, et al. Early experience with off-the-shelf endografts using a zone 0 proximal landing site to treat the ascending aorta and arch. J Thorac Cardiovasc Surg. 2014; 148:105-12.

6. Appoo JJ, Tse LW, Pozeg ZI, Wong JK, Hutchison SJ, Gregory AJ, et al. Thoracic aortic frontier: review of current applications and directions of thoracic endovascular aortic repair (TEVAR). Can J Cardiol. 2014;30: $52-63$.

7. Roselli EE, Idrees J, Greenberg RK, Johnston DR, Lytle BW. Endovascular stent grafting for ascending aorta repair in high-risk patients. J Thorac Cardiovasc Surg. 2015;149:144-51.

8. Vallabhajosyula P, Gottret JP, Bavaria JE, Desai ND, Szeto WY. Endovascular repair of the ascending aorta in patients at high risk for open repair. $J$ Thorac Cardiovasc Surg. 2015;149(2 Suppl):S144-50.

9. Etz CD, Plestis KA, Homann TM, Bodian CA, Di Luozzo G, Spielvogel D, et al. Reoperative aortic root and transverse arch procedures: a comparison with contemporaneous primary operations. J Thorac Cardiovasc Surg. 2008;136: 860-7.

10. Di Eusanio M, Berretta P, Bissoni L, Petridis FD, Di Marco L, Di Bartolomeo R. Re-operations on the proximal thoracic aorta: results and predictors of short- and long-term mortality in a series of 174 patients. Eur J Cardiothorac Surg. 2011;40: 1072-6.

11. Tittle SL, Lynch RJ, Cole PE, Singh HS, Rizzo JA, Kopf GS, et al. Midterm follow-up of penetrating ulcer and intramural hematoma of the aorta. J Thorac Cardiovasc Surg. 2002;123:1051-9.

12. Criado FJ. Aneurysm morphology matters: fusiform vs. saccular. J Endovasc Ther. 2013;20:207-9.
13. Turina MI, Shennib H, Dunning J, Cheng D, Martin J, Muneretto C, et al EACTS/ESCVS committee. EACTS/ESCVS best practice guidelines for reporting treatment results in the thoracic aorta. Eur J Cardiothorac Surg. 2009;35 927-30.

14. Society of Thoracic Surgeons. Committee to develop a national database for thoracic surgeons. Definitions of terms of the Society of Thoracic Surgeons national cardiac surgery database. Ann Thorac Surg. 1994;58: 271-3.

15. Fillinger MF, Greenberg RK, McKinsey JF, Chaikof EL. Society for Vascular Surgery Ad Hoc Committee on TEVAR Reporting Standards. Reporting standards for thoracic endovascular aortic repair (TEVAR). J Vasc Surg. 2010; 52:1022-33.

16. Lu Q, Feng J, Zhou J, Zhao Z, Bao J, Feng R, et al. Endovascular repair of ascending aortic dissection: a novel treatment option for patients judged unfit for direct surgical repair. J Am Coll Cardiol. 2013;61: 1917-24.

17. Sörelius K, Mani K, Björck M, Sedivy P, Wahlgren CM, Taylor P, et al. European MAA collaborators. Endovascular treatment of mycotic aortic aneurysms: a European multicenter study. Circulation. 2014;130:2136-42.

18. Roux D, Brouchet L, Rousseau H, Elghobary T, Glock Y, Fournial G. Treatmen of a fistula at the distal anastomosis after Bentall operation with endoluminal covered stent. Ann Thorac Surg. 2002;74:2189-90.

19. Coscas R, Javerliat I, Tofigh AM, Hebert T, Jablonski M, Cluzel P, et al. Pseudoaneurysm of a saphenous bypass treated with covered endograft in the ascending aorta. J Thorac Cardiovasc Surg. 2007;134:230-2.

20. Lin PH, Kougias P, Huynh TT, Huh J, Coselli JS. Endovascular repair of ascending aortic pseudoaneurysm: technical considerations of a common carotid artery approach using the Zenith aortic cuff endograft. J Endovasc Ther. 2007;14: 794-8.

21. Yuri K, Yamaguchi A, Hori D, Nemoto K, Kawaguchi S, Yokoi Y, et al. A fenestrated stent graft for endovascular repair of an ascending aortic pseudoaneurysm. Ann Vasc Dis. 2010;3:228-31.

22. Martin Pedrosa M, Revuelta NC, Alonso VG, González Fajardo JA, Vaquero Puerta C. Endovascular therapy of ascending thoracic aorta. Ann Vasc Surg. 2010;24:696-8.

23. Garg N, Bacharach JM, Reynolds TR. Endovascular repair of ascending aortic pseudoaneurysm. Ann Vasc Surg. 2011;25:696.e1-5.

24. Uchida K, Imoto K, Yanagi H, Machida D, Okiyama M, Yasuda S. Endovascular repair of ascending aortic rupture: effectiveness of a fenestrated stent-graft. J Endovasc Ther. 2010;17:395-8.

25. Gray BH, Langan EM III, Manos G, Bair L, Lysak SZ. Technical strategy for the endovascular management of ascending aortic pseudoaneurysm. Ann Vasc Surg. 2012;26:734-8

26. Gelpi G, Cagnoni G, Vanelli P, Antona C. Endovascular repair of ascending aortic pseudoaneurysm in a high-risk patient. Interact Cardiovasc Thorac Surg. 2012; 14:494-6.

27. Kato N, Shimono T, Hirano T, Ishida M, Yada I, Takeda K. Translumina placement of endovascular stent-grafts for the treatment of type A aortic dissection with an entry tear in the descending thoracic aorta. J Vasc Surg. 2001;34:1023-8.

28. Ye C, Chang G, Li S, Hu Z, Yao C, Chen W, et al. Endovascular stent-graft treatment for Stanford type A aortic dissection. Eur J Vasc Endovasc Surg. 2011;42:787-94.

29. Gerosa G, Bianco R, Bortolami A, Dal Lin C, Frigatti P, Tarantini G, et al. Transcatheter repair of combined ascending aortic pseudoaneurysm and aortic arch aneurysm through a cardiac transapical approach. Ann Thorac Surg. 2011; 92:2259-62.

30. Heye S, Daenens K, Maleux G, Nevelsteen A. Stent-graft repair of a mycotic ascending aortic pseudoaneurysm. J Vasc Interv Radiol. 2006;17(11 Pt 1) 1821-5.

31. Lin PH, Bush RL, Tong FC, Chaikof E, Martin LG, Lumsden AB. Intra-arterial thrombin injection of an ascending aortic pseudoaneurysm complicated by transient ischemic attack and rescued with systemic abciximab. J Vasc Surg. 2001;34:939-42.

32. De Boo DW, Mott N, Kavnoudias H, Walton A, Lyon SM. Endovascular closure of ascending aortic pseudoaneurysm with a type II Amplatzer vascular plug. Vasc Endovascular Surg. 2014;48:329-32.

33. Sultan S, Hynes N. One-year results of the multilayer flow modulator stent in the management of thoracoabdominal aortic aneurysms and type B dissections. J Endovasc Ther. 2013;20:366-77. 
34. Shahverdyan R, Gawenda M, Brunkwall J. Triple-barrel graft as a novel strategy to preserve supra-aortic branches in arch-TEVAR procedures: clinical study and systematic review. Eur J Vasc Endovasc Surg. 2013;45: 28-35.

35. Azuma T, Yokoi Y, Yamazaki K. The next generation of fenestrated endografts: results of a clinical trial to support an expanded indication for aortic arch aneurysm treatment. Eur J Cardiothorac Surg. 2013;44: e156-63.
36. Iung B, Laouénan C, Himbert D, Eltchaninoff H, Chevreul K, Donzeau-Gouge P, et al; FRANCE 2 Investigators. Predictive factors of early mortality after transcatheter aortic valve implantation: individual risk assessment using a simple score. Heart. 2014;100:1016-23.

Key Words: ascending aortic pseudoaneurysm, penetrating ulcer, thoracic endovascular aortic repair

Readers who found these articles interesting may also like to read the following papers found in recent and future issues of our sister publications, Seminars in Thoracic and Cardiovascular Surgery and Operative Techniques in Thoracic and Cardiovascular Surgery!

\section{Acquired: Aortic Disease}

Original Submission: Outcomes of Open Surgical Repair for Type B Dissecting Aortic Aneurysm with Alternative Methods in the Endovascular Stent Era. Mitsumasa Hata. Semin Thorac Cardiovasc Surg 2015; Summer; 27(2):106-112.

Editorial Commentary: It is Difficult to Compare Apples and Oranges: Acute and Chronic Type B Aortic Dissections, Complicated and Uncomplicated, are Different and Should be Treated as Such. Ourania Preventza. Semin Thorac Cardiovasc Surg 2015; Summer; 27(2):113-114.

News and Views: Treatment of Thoracic Aortic Aneurysm: Role of Earlier Intervention. Bulat A. Ziganshin. Semin Thorac Cardiovasc Surg 2015; Summer; 27(2);135-143. 